Document downloaded from:

http://hdl.handle.net/10251/150626

This paper must be cited as:

Ferri-Vicedo, P.; Li, C.; Paris, C.; Vidal Moya, JA.; Moliner Marin, M.; Boronat Zaragoza, M.; Corma Canós, A. (2019). Chemical and Structural Parameter Connecting Cavity Architecture, Confined Hydrocarbon Pool Species, and MTO Product Selectivity in SmallPore Cage-Based Zeolites. ACS Catalysis. 9(12):11542-11551.

https://doi.org/10.1021/acscatal.9b04588

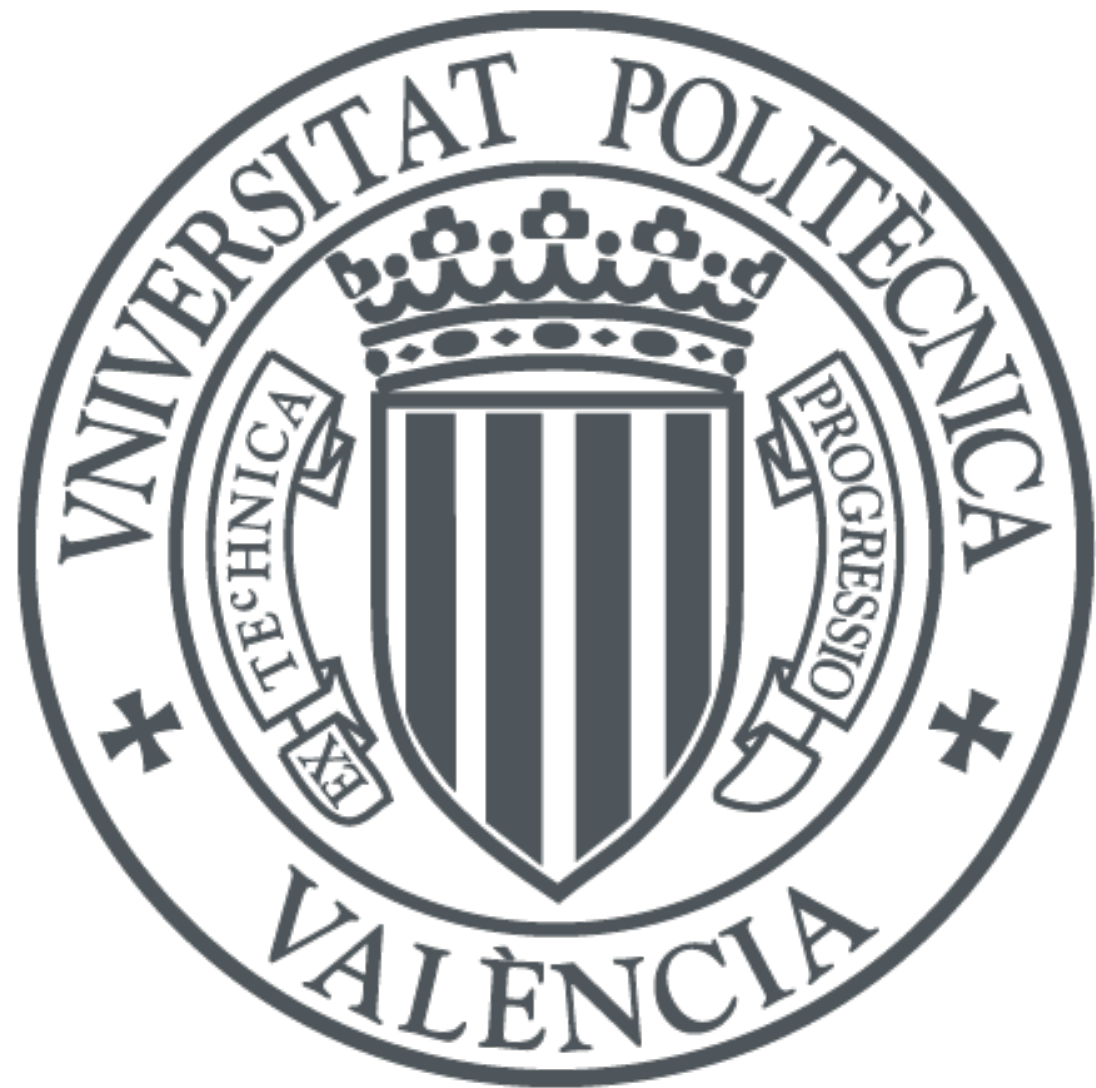

The final publication is available at

https://doi.org/10.1021/acscatal.9b04588

Copyright American Chemical Society

Additional Information

"This document is the Accepted Manuscript version of a Published Work that appeared in final form in ACS Catalysis, copyright (c) American Chemical Society after peer review and technical editing by the publisher. To access the final edited and published work see https://doi.org/10.1021/acscatal.9b04588" 


\title{
A Chemical and Structural Parameter Connecting Cavity Architecture, Confined Hydrocarbon Pool Species and MTO Product Selectivity in Small-Pore Cage-Based Zeolites
}

\author{
Pau Ferri ${ }^{\dagger}$ Chengeng Li ${ }^{\dagger}$ Cecilia Paris, Alejandro Vidal-Moya, Manuel Moliner, Mercedes \\ Boronat ${ }^{*}$ and Avelino Corma* \\ Instituto de Tecnología Química, Universitat Politècnica de València - Consejo Superior de Investigaciones \\ Cientificas, Av. de los Naranjos, s/n, 46022 Valencia, Spain
}

Supporting Information

\begin{abstract}
The catalysts used in the methanol-to-olefins reaction are considered dual systems comprising an inorganic zeolite framework and organic compounds hosted inside that act as co-catalyst. The influence of zeolite cavity architecture on the preferential stabilization of cationic intermediates involved in the paring and side-chain routes of the hydrocarbon pool mechanism is analyzed by means of DFT calculations, catalyst testing and ${ }^{13} \mathrm{C}$ NMR spectroscopy for some small-pore cage-based zeolites. A correlation between the degree of methylation of the entrapped methylbenzenium $\left(\mathrm{MB}^{+}\right)$cations and the selectivity to ethene and propene is found experimentally and explained in terms of the electronic distribution of the first intermediate of the paring route. A deep understanding of the reaction mechanism and of the specific host-guest interactions taking place inside zeolite catalysts allows establishing a quantitative parameter that is indicative for the contribution of the paring route and therefore the $\mathrm{C}_{3}{ }^{3} / \mathrm{C}_{2}=$ ratio in the MTO reaction.
\end{abstract}

KEYWORDS: MTO, zeolite, structure-selectivity relationship, DFT, mechanism

\section{INTRODUCTION}

The transformation of methanol into olefins, or MTO reaction, is one of the most successful processes to produce short-chain olefins at industrial scale. ${ }^{1,2}$ The MTO reaction is catalyzed by acid zeolites, whose microporous structure allocates and stabilizes the so-called hydrocarbon pool (HP) species, organic compounds that are formed during an initial induction period and act as co-catalysts for the reaction. ${ }^{3-5}$ The olefin products are formed by successive methylation and cracking of the HP intermediates, and therefore the catalyst can be considered a dual system comprising the inorganic zeolite framework and the organic species trapped inside. Small- pore zeolites containing large cavities within their structure are particularly suited for conversion of methanol into ethene $\left(\mathrm{C}_{2}{ }^{-}\right)$and propene $\left(\mathrm{C}_{3}{ }^{-}\right){ }^{2,6,7}$ and some commercial plants that employ $\mathrm{H}-$ SAPO-34 as catalyst are operating in China since $2010 .^{2}$

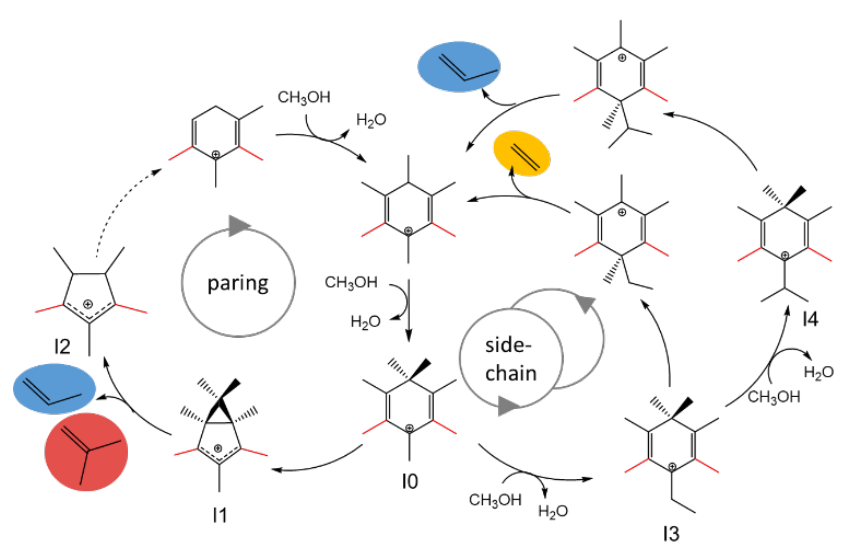

Scheme 1. Key cationic intermediates involved in the paring and side-chain routes of the aromatic-based hydrocarbon pool mechanism for the MTO reaction. Based on ref. [10].

The organic HP species in H-SAPO-34 and its aluminosilicate counterpart, SSZ-13, both with the CHA structure, are aromatic methyl-benzenes (MB) and their corresponding carbenium ions $\left(\mathrm{MB}^{+}\right)$, which participate in at least two possible competitive reaction pathways, the side-chain and the paring routes (see Scheme 1). Both processes share a common intermediate, labeled I0, which is formed by gem-methylation or attack of methanol to a tertiary carbon atom of the aromatic ring. The paring route starts 
with a ring-contraction of I0 to form a bicycle-hexenyl species I1 that splits off propene or isobutene generating cyclopentenyl $\left(\mathrm{CP}^{+}\right)$ cations, which expand again to yield $\mathrm{MB}^{+}$intermediates with a lower degree of methylation. The side-chain pathway involves exomethylation of the I0 intermediate to give I3, followed by some methyl-shift steps and side-chain elimination yielding preferentially ethene and propene. ${ }^{8-16}$

The two types of carbenium ions, $\mathrm{MB}^{+}$and $\mathrm{CP}^{+}$, have been detected by in situ ${ }^{13} \mathrm{C}$ NMR spectroscopy in small-pore zeolites with the CHA, AEI, RHO and LEV structures, ${ }^{17-21}$ showing the viability of the two mentioned pathways in these cage-based catalysts. It has also been reported that the contribution of each of the two pathways to the global conversion of methanol, and therefore to the final light olefin product distribution, depends on the topology of the zeolite cage. ${ }^{3,19,21-23}$ Very recently, the concept of cage-defining ring size has been introduced to classify small-pore cage-based zeolites into four structural categories that differ in their light olefin product distribution. ${ }^{24}$ However, the chemical origin of this behavior has not been clearly explained yet. Thus, while some authors claim that the final olefin product distribution is determined by differences in the diffusion of ethene and propene through the 8MR windows of the CHA structure, ${ }^{25}$ others propose, based on DFT calculations, a non-negligible contribution of an alkene-based catalytic cycle analogous to that operating in ZSM-5. ${ }^{11,16,26,27}$

Based on a newly developed concept,${ }^{28}$ we recently used mimics of the key intermediates involved the MTO reaction as organic structure directing agents (OSDAs) to synthesize zeolite catalysts that enhanced the contribution of the paring route, and therefore increased the selectivity to propene and butene. ${ }^{29}$ One of the findings of the theoretical study included in that work, confirmed by ${ }^{13} \mathrm{C}$ NMR spectroscopy, was the preferential stabilization of penta- $\mathrm{MB}^{+}$cations in CHA and hepta- $\mathrm{MB}^{+}$species in RTH. Considering that the stability of the bicycle-hexenyl intermediate formed in the first step of the paring route changed with the degree of methylation of the $\mathrm{MB}^{+}$precursor, it was proposed that the preferential stabilization of fully methylated species in RTH cages is the origin of the higher selectivity to propene and butenes obtained with this material.

Previous kinetic and ${ }^{13} \mathrm{C}$ NMR studies already reported that the selectivity to ethene and propene in H-SAPO-34 depends on the number of methyl groups in the $\mathrm{MB}^{+}$intermediates. ${ }^{30}$ In addition, a recent isotopic tracing study has demonstrated that the $\mathrm{C}_{3}=/ \mathrm{C}_{2}=$ ratio increases in an H-SAPO-34 sample entrained with a distribution of methylbenzenes deliberately manipulated towards increasing their degree of methylation. ${ }^{31}$ However, this effect is not permanent and after some cycles the selectivity tends to the values typically obtained with other CHA-type catalysts. Taking into account the hybrid organic-inorganic nature of the MTO catalysts and the influence of both cage architecture and degree of methylation of the aromatic HP species on the selectivity of the process, we have now analyzed in detail the paring route of the reaction mechanism to identify the key steps in which the specific interactions between a given zeolite framework and the hosted cationic intermediates might control the selectivity of the reaction. A series of small-pore zeolites with different cage topology have been synthesized and tested in the MTO reaction, and a clear linear correlation has been found between the relative stability of some key intermediates in each of these cages and the experimental $\mathrm{C}_{3}{ }^{=} / \mathrm{C}_{2}=$ ratio obtained.

\section{RESULTS AND DISCUSSION}

In a first step we investigated theoretically the successive methylation of benzenium cation with methanol, considering isolated organic species not stabilized within any zeolite model. We found, in agreement with previous work, ${ }^{32}$ that ring-methylation is an exothermic process that enables the formation of the fullysubstituted hexa- $\mathrm{MB}^{+}$cation through several consecutive steps (see Table S1 in the Supporting Information). Gem-methylation is only favored for systems with at least four methyl groups, ${ }^{8-9}$ so that both the ring- and gem-methylation of several tetra-, penta- and hexa$\mathrm{MB}^{+}$cations were considered (Figure 1 and Tables 1 and S1).

Starting from the most stable isomer of tetra- $\mathrm{MB}^{+}$cation $\left(4 \mathrm{MB}_{\mathrm{a}}{ }^{+}\right.$in Figure 1), ring-methylation producing $5 \mathrm{MB}^{+}$is slightly more favorable than gem-methylation to form the $\mathrm{g} 5 \mathrm{MB}^{+}$cation (see $\Delta \mathrm{G}_{\text {(ring) }}$ and $\Delta \mathrm{G}_{\text {(gem) }}$ values in Table 1$)$, which is considered one of the key intermediates of the MTO mechanism, while other gemmethylated isomers are significantly less stable. Gem-methylation of $4 \mathrm{MBb}^{+}$and $4 \mathrm{MB}^{+}$is also exothermic (Table $\mathrm{S} 1$ ), but the resulting $\mathrm{g} 5 \mathrm{MB}_{\mathrm{b}}{ }^{+}$and $\mathrm{g} 5 \mathrm{MB}_{\mathrm{c}}{ }^{+}$species can be directly converted into the most stable $5 \mathrm{MB}^{+}$via one intramolecular methyl shift with activation energies of $\sim 70 \mathrm{~kJ} \mathrm{~mol}^{-1}$ (values in blue in Figure 1). In contrast, the transformation of $\mathrm{g} 5 \mathrm{MB}^{+}$into $5 \mathrm{MB}^{+}$requires two consecutive methyl shifts and the intermediacy of the significantly less stable $1,1,2,3,5-5 \mathrm{MB}^{+}$cation (Figure 1 ). The thermodynamics of ring- and gem-methylation of $5 \mathrm{MB}^{+}$producing $6 \mathrm{MB}^{+}$and g6 $\mathrm{MB}^{+}$, respectively, are not too different (Table 1), and their interconversion involves two methyl shifts with the highest activation energy being $79 \mathrm{~kJ} \mathrm{~mol}^{-1}$. Finally, only gem-methylation yielding $\mathrm{g} 7 \mathrm{MB}^{+}$is possible for the fully methylated $6 \mathrm{MB}^{+}$cation.

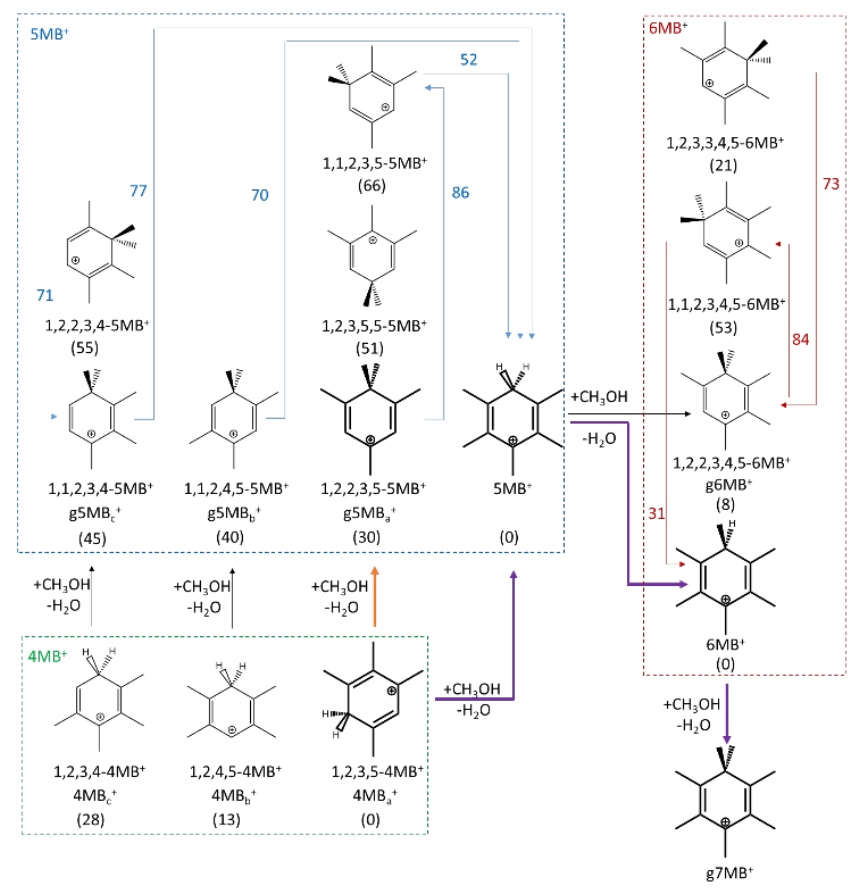

Figure 1. Possible pathways for methylation of $\mathrm{MB}^{+}$cations in gas phase, with the relative stability of isomers with the same stoichiometry $\left(4 \mathrm{MB}^{+}\right.$in the green box, $5 \mathrm{MB}^{+}$in the blue box, and $6 \mathrm{MB}^{+}$in the red box) given in parenthesis. Activation energies for intramolecular methyl-shifts are shown as colored numbers beside the arrows. All values are Gibbs free energies at $673 \mathrm{~K} \mathrm{in} \mathrm{kJ} \mathrm{mol}^{-1}$. Orange and purple arrows indicate species leading to side-chain and paring routes, respectively. 
Table 1. Gibbs free energies at $673 \mathrm{~K}$ (in $\mathrm{kJ} \mathrm{mol}^{-1}$ ) for the ring- and gem-methylation of $\mathrm{MB}^{+}$cations, and for the first step in the sidechain and paring routes of the MTO mechanism, in gas phase and within different zeolite cavities, and interaction energies ( $\left.E_{\text {int }}\right)$ between the key reaction intermediates and the zeolite cavities.

\begin{tabular}{|c|c|c|c|c|c|}
\hline$\Delta \mathrm{G}_{\text {(ring) }}$ & gas & CHA & AEI & RTH & ITE \\
\hline $4 \mathrm{MB}^{+} \rightarrow 5 \mathrm{MB}^{+}$ & -61.3 & -44.6 & -46.1 & -56.6 & -49.6 \\
\hline $5 \mathrm{MB}^{+} \rightarrow 6 \mathrm{MB}^{+}$ & -21.6 & -26.7 & -25.8 & -18.7 & -24.3 \\
\hline$\Delta \mathrm{G}_{(\mathrm{gem})}$ & gas & CHA & AEI & RTH & ITE \\
\hline $4 \mathrm{MB}_{\mathrm{a}}^{+} \rightarrow \mathrm{g} \mathrm{MB}_{\mathrm{a}}^{+}$ & -30.5 & -23.7 & -26.2 & -21.2 & -16.6 \\
\hline $5 \mathrm{MB}^{+} \rightarrow \mathrm{g} 6 \mathrm{MB}^{+}$ & -13.4 & -19.3 & -29.1 & -12.1 & -23.8 \\
\hline $6 \mathrm{MB}^{+} \rightarrow \mathrm{g} 7 \mathrm{MB}^{+}$ & -32.9 & 7.3 & -31.4 & -56.5 & -42.1 \\
\hline$\Delta \mathrm{G}_{(\text {paring })}$ & gas & CHA & AEI & RTH & ITE \\
\hline $\mathrm{g} 5 \mathrm{MB}_{\mathrm{a}}^{+} \rightarrow \mathrm{I} 1-5 \mathrm{MB}_{\mathrm{a}}^{+}$ & 110.7 & 102.9 & 121.2 & 116.2 & 111.6 \\
\hline $\mathrm{g} 6 \mathrm{MB}^{+} \rightarrow \mathrm{I} 1-6 \mathrm{MB}^{+}$ & 70.2 & 66.9 & & & 69.7 \\
\hline $\mathrm{g} \mathrm{MB}^{+} \rightarrow \mathrm{I} 1-7 \mathrm{MB}^{+}$ & 14.0 & -15.9 & -5.8 & 20.0 & 12.3 \\
\hline$\Delta \mathrm{G}_{(\text {side })}$ & gas & CHA & AEI & RTH & ITE \\
\hline $\mathrm{g} 5 \mathrm{MB}_{\mathrm{a}}^{+} \rightarrow \mathrm{I} 3-5 \mathrm{MB}^{+}$ & -33.7 & -41.0 & -38.0 & -38.0 & -27.6 \\
\hline $\mathrm{g} 6 \mathrm{MB}^{+} \rightarrow \mathrm{I} 3-6 \mathrm{MB}^{+}$ & -36.5 & -66.5 & & & -43.4 \\
\hline $\mathrm{g} \mathrm{MB}^{+} \rightarrow \mathrm{I} 3-7 \mathrm{MB}^{+}$ & -32.2 & -29.5 & -33.0 & -39.0 & -30.2 \\
\hline $\mathrm{E}_{\text {int }}$ & & CHA & AEI & RTH & ITE \\
\hline $\mathrm{g} \mathrm{MB}_{\mathrm{a}}^{+}$ & & -194.6 & -194.1 & -219.2 & -200.8 \\
\hline $\mathrm{g} \mathrm{MB}^{+}$ & & -149.4 & -190.0 & -243.9 & -218.4 \\
\hline
\end{tabular}

The equilibrium constants calculated at $400{ }^{\circ} \mathrm{C}, K_{\text {eq(ring) }}$ and $K_{\text {eq(gem), }}$ summarized in Table $\mathrm{S} 2$ indicate that, among the different cationic species studied, $\mathrm{g} 5 \mathrm{MB}^{+}, \mathrm{g} 6 \mathrm{MB}^{+}$and $\mathrm{g} 7 \mathrm{MB}^{+}$can be considered persistent intermediates (I0 in Scheme 1) able to react following any of the alternative routes proposed for the MTO reaction, while a much lower contribution of $\mathrm{g} 5 \mathrm{MB}_{\mathrm{b}}^{+}$and $\mathrm{g} 5 \mathrm{MB}_{\mathrm{c}}^{+}$should be expected. Notice that at this point the zeolite lattice was not yet taken into account, and therefore we should be cautious in interpreting the absolute quantitative values. The influence of the zeolite framework will be introduced later for selected reactions.

The side-chain path of the MTO mechanism starts with exomethylation of these I0 gem- $\mathrm{PMB}^{+}$cations generating ethylsubstituted species (I3 in Scheme 1), with calculated Gibbs free energies of reaction that do not change much with the degree of methylation of the $\mathrm{I} 0$ intermediates $\left(\Delta \mathrm{G}_{(\text {side })} \sim-35 \mathrm{~kJ} \mathrm{~mol}^{-1}\right.$, see gas in Table 1). In contrast, the stability of the bicycle-hexenyl cation (I1 in Scheme 1) formed in the first step of the paring route varies strongly with the substitution pattern in the aromatic ring. Thus, formation of $\mathrm{I} 1$ from $\mathrm{g} 7 \mathrm{MB}^{+}$cation is endothermic by $14 \mathrm{~kJ} \mathrm{~mol}^{-1}$, but the same process starting from $\mathrm{g} 5 \mathrm{MB}_{\mathrm{a}}^{+}$is energetically disfavoured by $111 \mathrm{~kJ} \mathrm{~mol}^{-1}$ (Table 1). Such large differences in stability can be understood by analysing the charge distribution, optimized geometry and molecular orbital composition of the I1 isomers (Figure 2). The optimized $\mathrm{C}-\mathrm{C}$ bond lengths and net atomic charges indicate that the positive charge in the most stable I1-7MB isomer is symmetrically distributed between two equivalent carbon atoms of the aromatic ring. Removal of only one methyl group, as in $\mathrm{I} 1-6 \mathrm{MB}^{+}$isomer, results in a different electron distribution, with one clear $\mathrm{C}=\mathrm{C}$ bond and with the positive charge localized on one of the methyl-substituted carbon atoms of the ring. The same electron distribution is found in $\mathrm{I} 1-5 \mathrm{MBb}^{+}$and $\mathrm{I} 1-5 \mathrm{MB}^{+}$, that gives rise to similar stabilities. In I1-5 $\mathrm{MB}^{+}$, however, the five-membered ring contains two $\mathrm{C}=\mathrm{C}$ bonds, and the positive charge is localized on the tertiary carbon atom where gem-methylation occurred, leading to rupture of one of the bonds in the three-membered ring and to a significantly less stable species (see Figure S1). Although the calculated activation energy barriers for this step are similarly high for all isomers considered, in the $140-170 \mathrm{~kJ} \mathrm{~mol}^{-1}$ range (Figure S1), the differences in stability of the bicyclic intermediates formed are large enough to determine their concentration in the reaction media, and therefore the probability of the reaction following this route (Figure S2). The equilibrium constants calculated at $400{ }^{\circ} \mathrm{C}$ for the first steps in the side-chain and paring pathways summarized in Table S2, indicate that, from the point of view of the intrinsic thermodynamic stability of the key intermediates, the paring route is only affordable for the fullymethylated $\mathrm{g} 7 \mathrm{MB}^{+}$cation. Therefore, a quantitative parameter trying to describe and predict the olefin distribution in the MTO reaction should include the stability and consequently the concentration of $\mathrm{g} 7 \mathrm{MB}^{+}$.
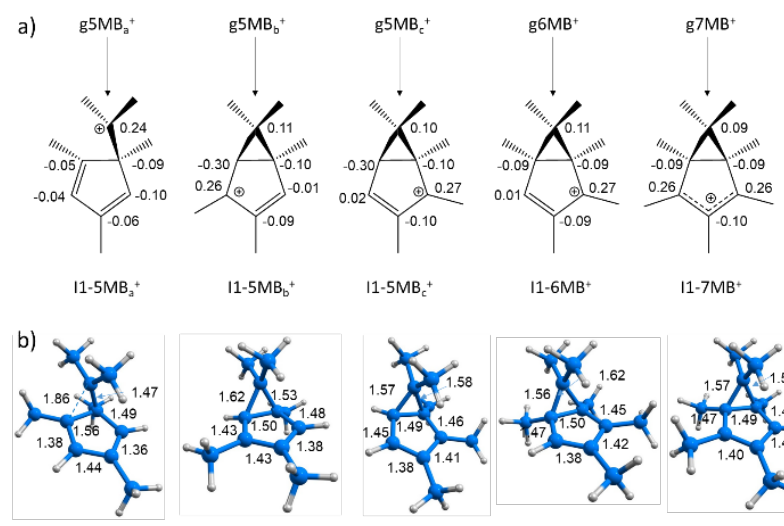

$-7 \mathrm{MB}^{+}$
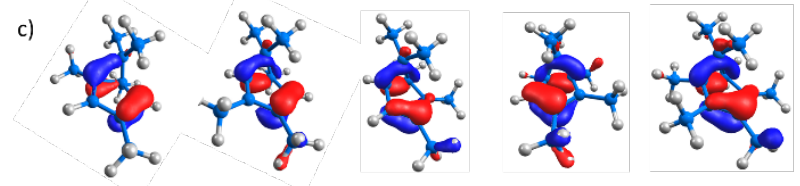

Figure 2. I1 intermediates with different degree of methylation formed in the first step of the paring route. a) Schematic representation of I1 including net atomic charges on the ring carbon atoms. b) Optimized geometries of I1 with calculated C-C bond length values in $\AA$. c) Orbital composition of the HOMO of each I1 intermediate.

Next, to evaluate whether the zeolite environment can modify the intrinsic reactivity of the isolated cations, the ring- and gemmethylation of $\mathrm{MB}^{+}$cations, as well as the first steps in the sidechain and paring routes described above, were re-calculated with these species placed inside four zeolite cavity models corresponding to CHA, AEI, RTH and ITE structures (Figure 3). The four zeolites contain cages of similar dimensions and different shapes, which are accessible through eight-membered ring (8R) windows. They also differ in the dimensionality of their pore system, three-directional for CHA and AEI, and two-directional for RTH and ITE. The Brönsted acidic site was not explicitly accounted in these calculations, as we wanted to study particularly the effect of the zeolite cage topology on the stabilization of the key organic intermediates and transition states. However, preliminary studies introducing Brönsted acid sites in different positions in the CHA cavity do not reveal a significant influence beyond the particular stabilizing effect introduced by the zeolite cage topology. 

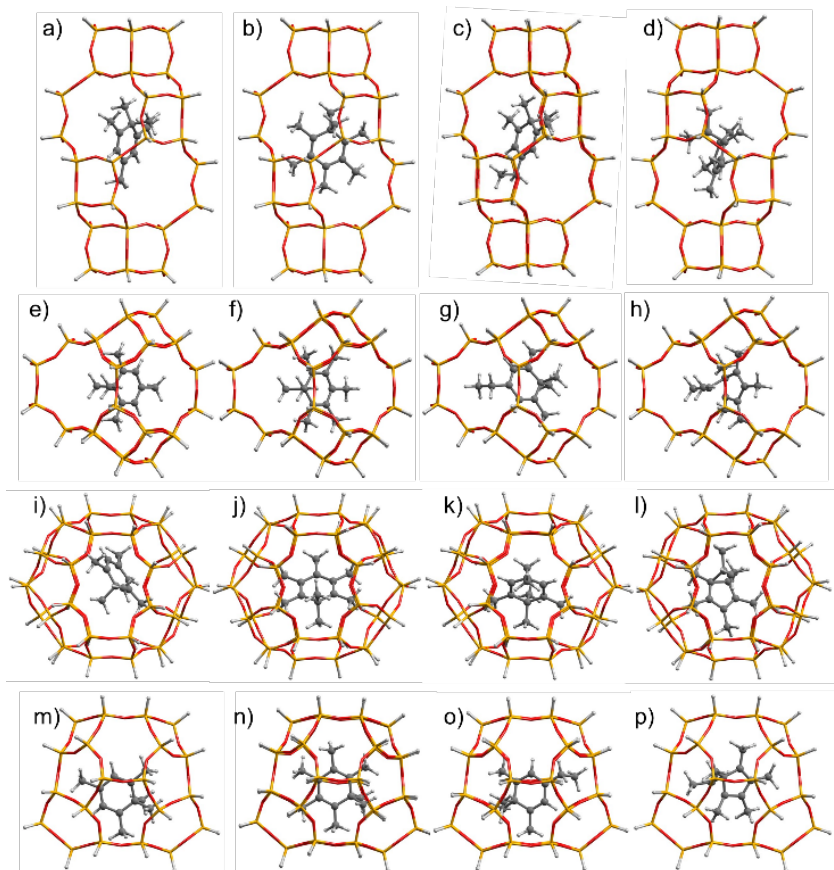

Figure 3. Optimized structures of gem- $5 \mathrm{MB}^{+}$(a, e, i, m), $7 \mathrm{MB}^{+}$ $(\mathrm{b}, \mathrm{f}, \mathrm{j}, \mathrm{n}), \mathrm{I} 3$-side- $5 \mathrm{MB}_{\mathrm{a}}^{+}(\mathrm{c}, \mathrm{g}, \mathrm{k}, \mathrm{o})$ and I1-paring-7 $\mathrm{MB}^{+}(\mathrm{d}, \mathrm{h}, \mathrm{l}$, p) intermediates placed in the CHA (a, b, c, d), AEI (e, f, g, h), RTH $(\mathrm{I}, \mathrm{j}, \mathrm{k}, \mathrm{l})$ and $\operatorname{ITE}(\mathrm{m}, \mathrm{n}, \mathrm{o}, \mathrm{p})$ cavity models.

The different topology of the four cages plays a key role in the stabilization of the reaction intermediates investigated. Thus, the thermodynamic preference for ring- versus gem-methylation of $4 \mathrm{MB}_{\mathrm{a}}^{+}$found in the gas phase, is enhanced in RTH and ITE zeolites (Tables 1 and S2), while the CHA and AEI structures have the opposite effect and gem-methylation becomes almost competitive, especially in CHA $\left(K_{\text {eq(ring })} / K_{\text {eq }(g e m)}\right.$ ratio $\left.=10\right)$. This could be related to the three-fold symmetry of the CHA cage that does not allow all the methyl groups of the higher-methylated planar intermediates to point towards $8 \mathrm{R}$ windows to avoid steric repulsions. Due to its smaller size, the $\mathrm{g} 5 \mathrm{MB}_{\mathrm{a}}^{+}$can rotate and move within the CHA cavity to minimize such repulsions (Figure 3 ). The influence of the cage on the gem-methylation of $6 \mathrm{MB}^{+}$cation is also relevant, with the calculated $\Delta \mathrm{G}_{(\mathrm{gem})}$ values increasing to -57 and $-42 \mathrm{~kJ} \mathrm{~mol}^{-1}$ in ITE and RTH, remaining as in the gas phase in AEI, and becoming slightly endothermic in CHA (Table 1). Again, this is due to a better fitting of the higher-methylated planar intermediates within the two-fold symmetry of the RTH and ITE cavities, while the particular shape of the AEI cage, also with a $3 \mathrm{D}$ pore system, allows a better accommodation of $\mathrm{g} 7 \mathrm{MB}^{+}$than $\mathrm{CHA}$. These data indicate that the degree of ring-methylation of $\mathrm{MB}^{+}$ intermediates trapped in CHA will be significantly lower than in the other structures. And, in turn, this has an effect on the probability of the MTO reaction to follow the paring route.

To confirm the trends arising from the relative stability of reaction intermediates, we studied the first steps of the paring mechanism for $\mathrm{g} 5 \mathrm{MB}_{\mathrm{a}}{ }^{+}$and $\mathrm{g} 7 \mathrm{MB}^{+}$cations in each of the four different zeolite structures considered, including geometry optimization of both minima and transition states. Previous computational studies report high activation energies, around $100 \mathrm{~kJ} \mathrm{~mol}^{-1}$, for several elementary steps of the side-chain pathway in H-SAPO-34 (exomethylation, intramolecular methyl-shifts and side-chain ethene elimination), ${ }^{11,12,16}$ which are comparable to the activation energies obtained here for the ring contraction step that starts the paring route.

The Gibbs free energy profiles obtained for $\mathrm{g} 5 \mathrm{MB}_{\mathrm{a}}^{+}$cation in different cages are equivalent (Figure 4a), suggesting that none of these zeolites would in principle modify the probability of the reaction to start following the side-chain pathway. In contrast, the stability of $\mathrm{g} 7 \mathrm{MB}^{+}$cation depends strongly on the zeolite framework (Figure 4b), with the I0 intermediate being up to $117 \mathrm{~kJ}$ mol $^{-1}$ more stable in RTH than in CHA. As described before, the paring route is energetically affordable only for the fullymethylated $\mathrm{g} \mathrm{MB}^{+}$cation, whose concentration should be, according to the data in Figure 4, much larger in RTH and ITE than in CHA, with AEI being in an intermediate situation. On the other hand, formation of propene through I4 intermediate following the side-chain pathway is energetically disfavored in AEI, RTH and ITE (Table S3) and, despite being feasible in CHA, isotopic labelling studies have shown that propene in CHA is formed via the paring route, ${ }^{31}$ and computational studies report higher barriers for propene formation following the side-chain pathway. ${ }^{16,21}$
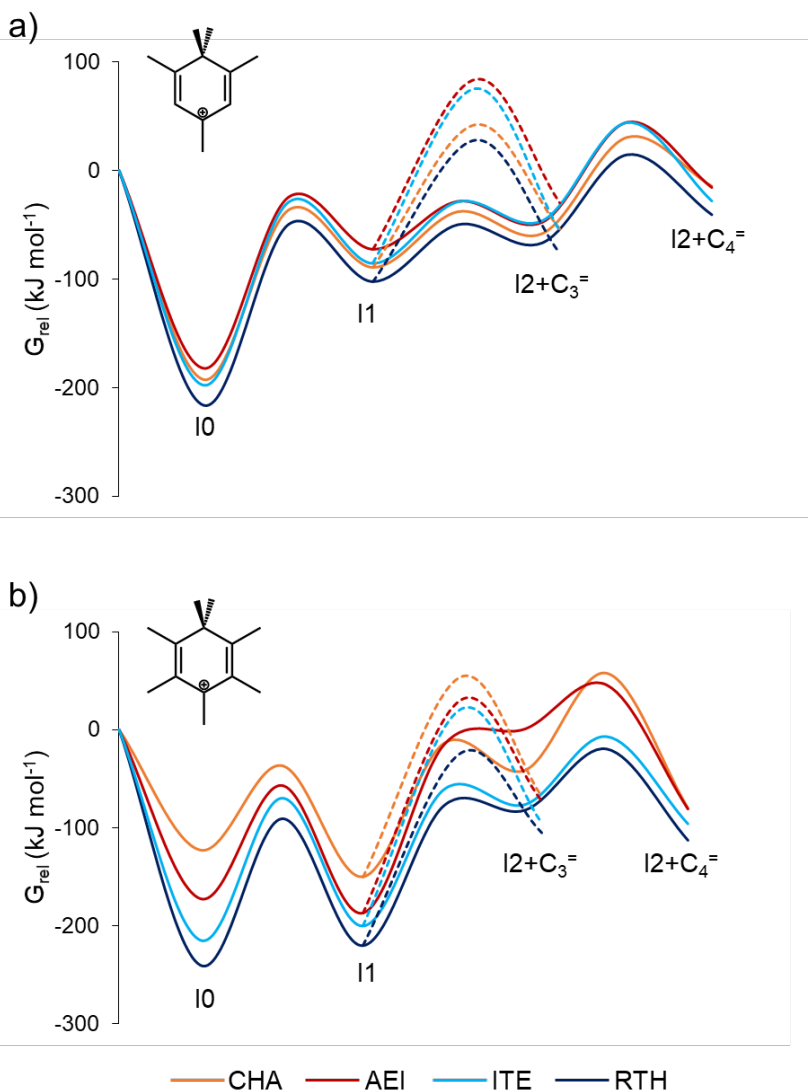

Figure 4. Gibbs free energy profile for the first part of the paring pathway leading to propene (dashed lines) and butene (full lines) for a) $\mathrm{g} 5 \mathrm{MBa}^{+}$and b) $\mathrm{g} 7 \mathrm{MB}^{+}$cations within the $\mathrm{CHA}$ (yellow) AEI (red) ITE (cyan) and RTH (blue) cavity models. The origin of energies $(G=0)$ is the sum of the energies of the zeolite cluster model and the corresponding $\mathrm{MB}^{+}$cation. The energy values are given in Table S4 in the Supporting Information. 
In summary, the DFT study shows that the relative stability of some reaction intermediates, in particular of the $\mathrm{g} 7 \mathrm{MB}^{+}$cation that starts the paring route, is modified when they are confined in zeolites with different cage topology. In CHA, gem-methylation of $4 \mathrm{MB}^{+}$ intermediate is competitive, and starts the side-chain pathway that produces ethene. AEI is able to accommodate $\mathrm{g} 7 \mathrm{MB}^{+}$better than CHA, while full ring-methylation is preferred in RTH and ITE, resulting in a higher concentration of $\mathrm{g} 7 \mathrm{MB}^{+}$cation and therefore an enhancement of the paring route producing propene and butene.

At this point, we would like to connect the mechanisms proposed theoretically with experimental evidences, including both catalytic tests and advanced characterization techniques. Different cagebased small pore zeolites with the CHA (SSZ-13), AEI (SSZ-39), RTH (RUB-13) and ITE (ITQ-3) frameworks and each of them with different physico-chemical properties were synthesized (see details in the Experimental Section). ${ }^{33,34}$ The as-synthesized small pore zeolites show the characteristic PXRD patterns of CHA, AEI, RTH and ITE structures (Figure S3) and, as shown in Figure S4 and Table S6, the crystal size and/or chemical composition of the proposed zeolites can be tuned. Indeed, four different CHA materials were prepared with $\mathrm{Si} / \mathrm{Al}$ molar ratios ranging from $\sim 15$ (CHA-1 and CHA-3) to 25 (CHA-2 and CHA-4), and crystal sizes between 60-90 nm (CHA-3 and CHA-4) and $1 \mu \mathrm{m}$ (CHA-1 and CHA-2). SSZ-39 was prepared with similar $\mathrm{Si} / \mathrm{Al}$ molar ratios but different crystal sizes, from nano-crystals of $\sim 60 \mathrm{~nm}$ (AEI-2) to large crystals of 300-400 nm (AEI-1). RUB-13 was prepared with $\mathrm{Si} / \mathrm{Al} \sim 12-15$, either as nanocrystallites of $\sim 70-90 \mathrm{~nm}(\mathrm{RTH}-1)$ or as micron-sized particles of 1-2 $\mu \mathrm{m}$ (RTH-2), and ITQ-3 was synthesized with a $\mathrm{Si} / \mathrm{Al}$ molar ratio of $\sim 13$, with intermediate crystal sizes $(0.5 \times 0.2 \mu \mathrm{m}$, Figure $\mathrm{S} 4)$. The textural properties of the calcined materials determined by $\mathrm{N}_{2}$ adsorption experiments are analogous to those reported in the literature (Table S6), and most of the $\mathrm{Al}$ species remain in tetrahedral coordination within the zeolite frameworks, as revealed by ${ }^{27} \mathrm{Al}$ MAS NMR (Figure S5).

Table 2. Product selectivity at the same methanol conversion level $(\mathrm{X}=95 \%)$ for the different small pore zeolites with TOS. Reaction conditions: $\mathrm{T}=350$ or $400^{\circ} \mathrm{C}$, WHSV $=0.8 \mathrm{~h}^{-1}$, $\mathrm{w}_{\text {cat }}=50 \mathrm{mg}$.

\begin{tabular}{cccccccc}
\hline \multicolumn{7}{c}{$\begin{array}{c}\text { Lifetime } \\
\text { (min) }\end{array}$} & \multicolumn{5}{c}{$\begin{array}{c}\text { Selectivity } \\
(\% \mathrm{wt})\end{array}$} \\
Sample & $\mathrm{T}\left({ }^{\circ} \mathrm{C}\right)$ & $\mathrm{X}_{95}$ & $\mathrm{C}_{2}=$ & $\mathrm{C}_{3}=$ & $\mathrm{C}_{4}=$ & $\mathrm{C}_{3}=/ \mathrm{C}_{2}=$ & $\mathrm{C}_{4}=/ \mathrm{C}_{2}=$ \\
\hline CHA-1 & 350 & 260 & 45.1 & 37.0 & 12.4 & 0.82 & 0.27 \\
CHA-2 & 350 & 117 & 44.1 & 36.6 & 13.0 & 0.83 & 0.29 \\
CHA-3 & 350 & 1085 & 47.1 & 34.2 & 12.1 & 0.73 & 0.26 \\
CHA-4 & 350 & 564 & 46.8 & 35.1 & 12.3 & 0.75 & 0.26 \\
AEI-1 & 350 & 408 & 19.6 & 49.4 & 21.6 & 2.50 & 1.10 \\
AEI-2 & 350 & 480 & 22.6 & 47.9 & 22.0 & 2.20 & 0.98 \\
RTH-1 & 350 & 270 & 14.7 & 45.1 & 24.7 & 3.07 & 1.68 \\
ITE & 350 & 217 & 13.7 & 42.6 & 28.2 & 3.11 & 2.06 \\
\hline CHA-1 & 400 & 670 & 56.4 & 30.4 & 9.2 & 0.54 & 0.16 \\
AEI-1 & 400 & 446 & 33.6 & 44.5 & 14.2 & 1.32 & 0.42 \\
RTH-1 & 400 & 236 & 27.6 & 44.2 & 16.8 & 1.60 & 0.61 \\
RTH-2 & 400 & 105 & 26.9 & 42.9 & 14.8 & 1.60 & 0.55 \\
ITE & 400 & 378 & 24.4 & 47.8 & 20.6 & 1.95 & 0.84 \\
\hline
\end{tabular}
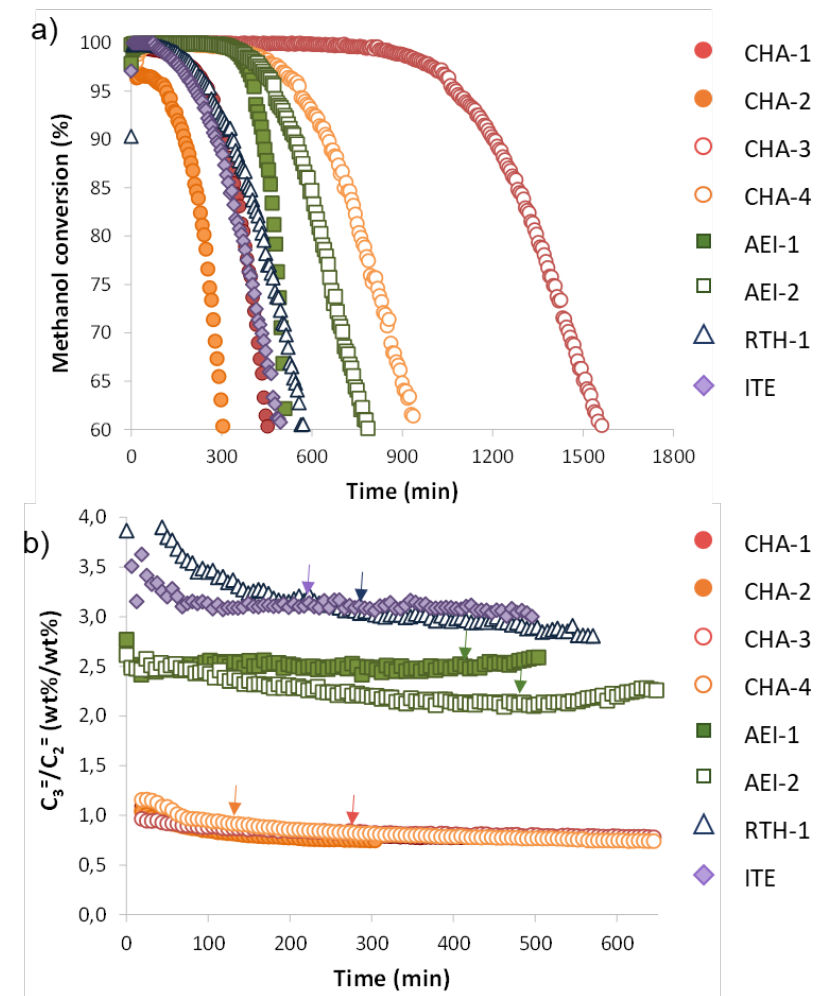

Figure 5. Methanol conversion (a) and $\mathrm{C}_{3}=/ \mathrm{C}_{2}{ }^{=}$ratio (b) vs time on stream for different small pore zeolites. Reaction conditions: $\mathrm{T}=350^{\circ} \mathrm{C}$, WHSV $=0.8 \mathrm{~h}^{-1}, \mathrm{w}_{\mathrm{cat}}=50 \mathrm{mg}$. The arrows indicate the $\mathrm{C}_{3}=/ \mathrm{C}_{2}=$ ratio at $95 \%$ methanol conversion.

These catalysts were first tested for the MTO reaction at $350^{\circ} \mathrm{C}$ with a WHSV of $0.8 \mathrm{~h}^{-1}$. Under these conditions, their methanol conversion profiles are clearly different, as depicted in Figure 5. As a general approximation, larger catalyst lifetimes are observed when the crystal sizes are decreased for a given structure with comparable $\mathrm{Si} / \mathrm{Al}$ molar ratios (Table 2). For instance, CHA-1 and CHA-3 materials, with similar $\mathrm{Si} / \mathrm{Al}$ ratio but clearly different crystal size, require 260 and $1085 \mathrm{~min}$, respectively, to achieve a methanol conversion drop to 95\% (Table 2, and Figures 4a, S6a and S8a). The same trend is found when comparing CHA-2 and CHA-4, or AEI-1 and AEI-2 although less pronounced in this last case. However, the analysis of their product distributions when the different catalysts are compared at the same conversion level (X 95\%) clearly reveals a direct relationship between the products formed and the framework topologies, regardless their crystal size and/or chemical composition. In fact, the $\mathrm{C}_{3}=/ \mathrm{C}_{2}=$ and $\mathrm{C}_{4}=/ \mathrm{C}_{2}{ }^{=}$ratios of the four different CHA catalysts at $95 \%$ methanol conversion give analogous values of $\sim 0.8$ and $\sim 0.3$, respectively (Table 2 ) but, even more interestingly, these ratios remain almost unaltered with TOS during the MTO reaction (Figure 5b and S6c-S9c). The other small pore zeolites (AEI, RTH and ITE) produce more propene and butene than ethene as compared to CHA. It is worth noting that the overall product selectivity for each zeolite framework mostly remain unaltered when compared at the same conversion level and/or different TOS, even when the physico-chemical properties of the crystals are substantially modified (Figures $5 \mathrm{~b}$ and S10c$\mathrm{S} 13 \mathrm{c})$. Interestingly, there is an experimental correlation between 
propene and butene selectivity for the different small pore zeolites, where the order found for the $\mathrm{C}_{3}{ }^{=} / \mathrm{C}_{2}{ }^{=}$and $\mathrm{C}_{4}{ }^{\prime} / \mathrm{C}_{2}=$ ratios at $350^{\circ} \mathrm{C}$ is ITE $>\mathrm{RTH}>\mathrm{AEI}>\mathrm{CHA}$ (Table 2). This order is maintained when the different zeolite frameworks are tested at $400^{\circ} \mathrm{C}$ (Table 2 and Figures S14-S18).

Although it is not possible to absolutely rule out an influence of diffusion issues through the zeolite windows in this work, ${ }^{25}$ the trends in selectivity observed for the zeolite structures studied can be mostly associated to the nature of the zeolite cages. ${ }^{21,23,29}$ According to molecular dynamics studies, diffusion of ethene and propene in zeolites with $12 \mathrm{MR}$ or $10 \mathrm{MR}$ openings like BEA, FAU or MFI is almost unrestricted, with self-diffusion coefficient ratios of ethene to propene around 2. In contrast, diffusion of propene through the 8MR windows of CHA becomes sterically hindered and the self-diffusion coefficient ratio of ethene to propene increases to 20-40 depending on the temperature. ${ }^{35}$ Since ethene diffuses much more easily than propene in zeolites containing $8 \mathrm{MR}$ windows, ${ }^{36}$ the observation of $\mathrm{C}_{3}=/ \mathrm{C}_{2}=$ ratios larger than unity in some of the structures indicates that propene is formed in much larger amounts in these materials, in agreement with the DFT results.

Thus, considering the theoretical calculations presented above, it could be argued that the maximization of the propene and butene yields when using ITE and RTH would be related to their better ability to stabilize the fully-methylated HP species that favor the paring route, whereas partly-methylated aromatic intermediates should be preferentially stabilized within the CHA cavities. To evaluate properly the nature of the HP species along the different small-pore zeolites, the MTO reaction was carried out using ${ }^{13} \mathrm{C}$ labelled methanol at 350 or $400^{\circ} \mathrm{C}$ (see details in Experimental Section), and the used catalysts were characterized by ${ }^{13} \mathrm{C}$ MAS NMR spectroscopy. Two well-differentiated regions appear in the ${ }^{13} \mathrm{C}$ MAS NMR spectra presented in Figures 6 and S19, one between 155 and $110 \mathrm{ppm}$ assigned to the aromatic carbons present in the HP ( $\left.\mathrm{C}_{\text {arom }}\right)$, and another between 25 and $10 \mathrm{ppm}$ assigned to alkyl-substituent carbon groups $\left(\mathrm{C}_{\text {alk }}\right)$. From the ${ }^{13} \mathrm{C} \mathrm{CP} / \mathrm{MAS}$ refocused INADEQUATE spectrum (Figure S20) it is possible to differentiate between methylated $\left(\mathrm{C}_{\mathrm{A}}\right)$ and non-methylated $\left(\mathrm{C}_{\mathrm{B}}\right)$ aromatic carbons, highlighted in blue and yellow, respectively, in Figures 6 and S19. The integration of the signals area attributed to these types of aromatic carbons allows obtaining a quantification of the degree of alkylation of the hydrocarbon pool for the different catalysts (Table S7). Thus, both the $\mathrm{C}_{\mathrm{A}} / \mathrm{C}_{\mathrm{B}}$ ratio and the $\mathrm{C}_{\text {alk }} / \mathrm{C}_{\text {arom }}$ ratios at $400^{\circ} \mathrm{C}$ are remarkably higher for ITE and $\mathrm{RTH}$ than for $\mathrm{CHA}$, confirming the conclusions from the theoretical study.

According to the present mechanistic proposal, the contribution of the paring route is determined by the ability of each cage to host the fully-methylated $\mathrm{g} 7 \mathrm{MB}^{+}$cation in comparison with the g5 $\mathrm{MBa}^{+}$ cation that initiates the side-chain pathway. This ability is quantitatively described by the interaction energy between the cation and the cavity model $\left(\mathrm{Eint}_{\mathrm{in}}\left(\mathrm{MBBa}{ }^{+}\right)\right.$and $\left.\mathrm{E}_{\text {int }\left(\mathrm{g} 7 \mathrm{MB}^{+}\right)}\right)$in Table 1) and therefore we can define an interaction energy ratio $\mathrm{E}_{\text {int }(7 / 5)}$ as

$$
\operatorname{Eint}(7 / 5)=\operatorname{Eint}\left(\mathrm{g} 7 \mathrm{MB}^{+}\right) / \operatorname{Eint}_{\text {int }}\left(\mathrm{g} \mathrm{MBa}^{+}\right)
$$

Indeed, a clear linear relationship is found between the measured $\mathrm{C}_{3}{ }=/ \mathrm{C}_{2}=$ ratios and the $\mathrm{E}_{\text {int }(7 / 5)}$ parameter calculated for the four zeolites investigated in this work (Figure 7a), and for other reaction conditions and zeolite structures reported in the bibliography $y^{23,24}$ (Figure 7b).

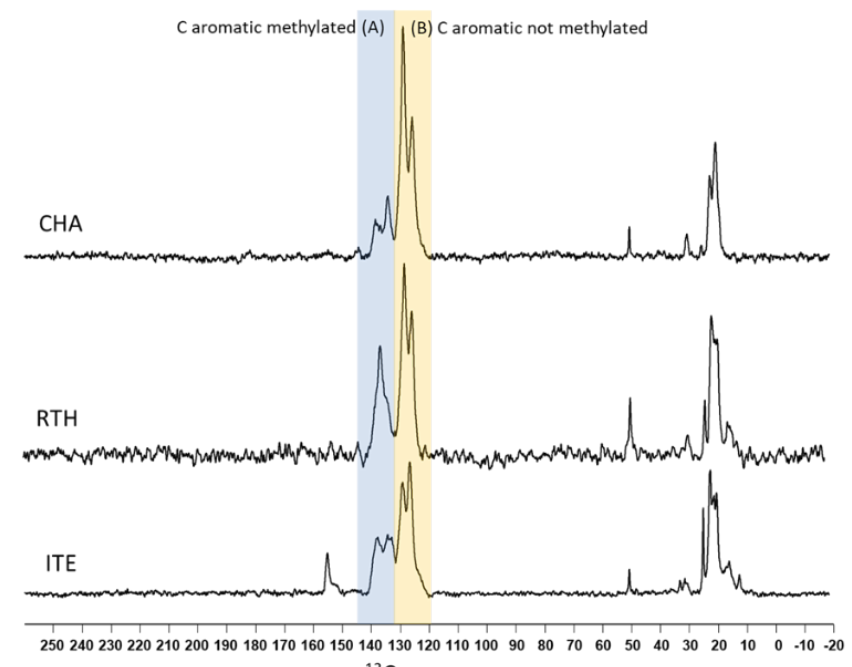

${ }^{13} \mathrm{C}(\mathrm{ppm})$

Figure 6. ${ }^{13} \mathrm{C}$ MAS NMR spectra of the retained organic species in CHA, RTH and ITE after performing the MTO reaction with ${ }^{13} \mathrm{C}$ labelled methanol at $400^{\circ} \mathrm{C}$ for $2 \mathrm{~min}$.
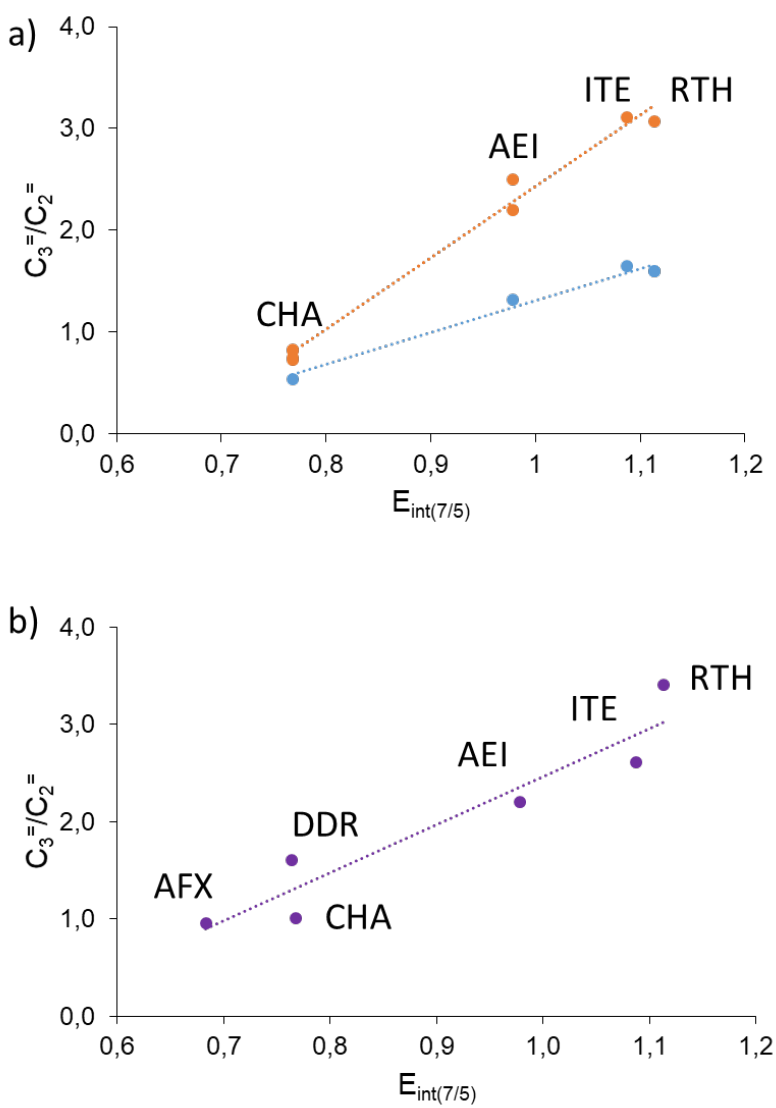

Figure 7. Relationship between measured $\mathrm{C}_{3}{ }=/ \mathrm{C}_{2}{ }^{=}$ratio and $\operatorname{Eint}(7 / 5)$ parameter in different small-pore cage-based zeolites. Reaction conditions: a) $\mathrm{WHSV}=0.8 \mathrm{~h}^{-1}, \mathrm{~T}=400^{\circ} \mathrm{C}$ (blue) and $\mathrm{T}=350^{\circ} \mathrm{C}$ (orange), data from this work, b) $\mathrm{WHSV}=1.3 \mathrm{~h}^{-1}, \mathrm{~T}=400^{\circ} \mathrm{C}$, data from reference [23]. 


\section{CONCLUSIONS}

In summary, it is proposed from DFT calculations and experimentally confirmed through catalytic tests and ${ }^{13} \mathrm{C} N \mathrm{NMR}$ spectroscopy that the product distribution of the MTO reaction catalyzed by small-pore cage-based zeolites is determined by the ability of the catalyst cages to stabilize fully methylated $\mathrm{MB}^{+}$ intermediates through specific interactions that depend on the cavity topology. First, A DFT study of the main steps of the paring route for penta- $\mathrm{MB}^{+}$and hepta- $\mathrm{MB}^{+}$cations in $\mathrm{CHA}, \mathrm{AEI}, \mathrm{RTH}$ and ITE catalyst models shows a preferential stabilization of the fully-methylated intermediates in RTH and ITE, which is confirmed by ${ }^{13} \mathrm{C}$ NMR spectroscopy. Then, catalytic tests in the MTO reaction of a series of catalysts with different physicochemical properties shows that the olefin product distribution does not change significantly with $\mathrm{Si} / \mathrm{Al}$ ratio or crystal size, but with zeolite structure. Taking all these results together, it is proposed and demonstrated that small differences in the topology of the zeolite cavity can lead to a preferential stabilization of partly- or fully-methylated intermediates within the host cavity, which is reflected in a different product distribution. Finally, a quantitative parameter, the interaction energy ratio $E_{\text {int( }(7 / 5) \text {, is proposed to }}$ predict the contribution of the paring route and therefore the product distribution in this type of catalysts. This parameter could be used for a preliminary estimation of selectivity when using new or hypothetical zeolite structures.

\section{EXPERIMENTAL SECTION}

4.1. Computational Details. All calculations are based on density functional theory (DFT) and were carried out using the M062X functional ${ }^{37}$ and the $6-31 \mathrm{~g}(\mathrm{~d}, \mathrm{p})$ basis set, ${ }^{38}$ as implemented in the Gaussian09 software. ${ }^{39}$ In the study of the gas-phase reaction mechanism the positions of all $\mathrm{C}$ and $\mathrm{H}$ atoms in the cationic intermediates and transition states were fully optimized without restrictions. All stationary points were characterized by means of harmonic frequency calculations, which also provided the thermal corrections to calculate Gibbs free energies at standard state conditions in the gas phase and within the zeolite cages. In a second step, pure silica cluster models of the CHA, AEI, RTH and ITE cavities, of composition $\mathrm{Si}_{48} \mathrm{O}_{78} \mathrm{H}_{36}, \mathrm{Si}_{36} \mathrm{O}_{54} \mathrm{H}_{36}, \mathrm{Si}_{40} \mathrm{O}_{60} \mathrm{H}_{40}$ and $\mathrm{Si}_{40} \mathrm{O}_{60} \mathrm{H}_{40}$ respectively, were constructed from the corresponding periodic structures. The cationic intermediates and transition states were then placed inside each of these cluster models and their geometry fully re-optimized without restrictions while keeping the positions of the $\mathrm{Si}, \mathrm{O}$ and terminal $\mathrm{H}$ atoms of the clusters fixed. Using this approach, the possibility to obtain small energy differences associated to the relative position of the organic species and the Al centers is discarded, and only the influence of confinement effects associated to the fitting of the organic intermediates within the zeolite cages is evaluated. Equilibrium constants for the different reaction steps $K_{\text {reac }}$ were calculated as:

$$
K_{\text {reac }}=e^{-\Delta G_{\text {reac }} / R T}
$$

where $\Delta \mathrm{G}_{\mathrm{reac}}$ is the change in the Gibbs free energy, calculated as:

$$
\Delta \mathrm{G}_{\text {reac }}=\mathrm{G}_{\text {products }}-\mathrm{G}_{\text {reactants }}
$$

Interaction energies $\mathrm{E}_{\text {int }}$ were calculated as the difference in energy between the global system composed by the organic cation inside the zeolite cage model and the sum of the energies of the isolated cation and cluster model. Net atomic charges were obtained using the Natural Bond Order (NBO) analysis ${ }^{40}$ as implemented in Gaussian 09 software.

4.2. Synthesis of organic structure directing agents (OSDA). The synthesis of N,N,N-trimethyladamantamonium (TMAda), N,N-dimethyl-3,5-dimethylpiperidinium (DMDP), 1,2,3,4,5pentamethyl-1H-imidazol-3-ium (PMI) and methyltertbutylphosphonium (MTBP) organic structure directing agents is described in detail in the Supporting Information.

4.3. Synthesis of zeolites. Different cage-based small pore zeolites with the CHA (SSZ-13), AEI (SSZ-39), RTH (RUB-13) and ITE (ITQ-3) frameworks with different physico-chemical properties were synthesized following procedures from the literature. ${ }^{29,33,34}$ Experimental details for each synthesis can be found in the Supporting Information.

4.4. Characterization. Powder X-ray diffraction (PXRD) measurements were performed with a multisample Philips X'Pert diffractometer equipped with a graphite monochromator, operating at $40 \mathrm{kV}$ and $35 \mathrm{~mA}$, and using $\mathrm{Cu} \mathrm{K} \alpha$ radiation $(\lambda=0.1542 \mathrm{~nm})$. The morphology and particle size of the zeolites were characterized by Scanning Electron Microscope (SEM, JEOL JSM-6300). The chemical composition of the solid samples was determined by inductively coupled plasma atomic absorption spectroscopy (ICPOES) using a Varian 715-ES. Textural properties were determined by $\mathrm{N}_{2}$ adsorption isotherms measured at $77 \mathrm{~K}$ with a Micromeritics ASAP 2020

Solid state MAS NMR spectra were recorded with a Bruker AV400 III HD spectrometer. ${ }^{27} \mathrm{Al}$ MAS NMR spectra were recorded at spinning rate of $20 \mathrm{kHz}$ with a $90^{\circ}$ pulse length of $0.5 \mu \mathrm{s}$ with $1 \mathrm{~s}$ repetition time. The ${ }^{27} \mathrm{Al}$ chemical shift was referred to $\mathrm{Al}\left(\mathrm{H}_{2} \mathrm{O}\right)_{6}$. ${ }^{13} \mathrm{C}$ MAS NR spectra were recorded at spinning rate of $15 \mathrm{kHz}$ with a $90^{\circ}$ pulse length of 5 us using high-power proton decoupling (spinal64) $\mu$ s with 20 s repetition time. $2 \mathrm{D}{ }^{13} \mathrm{C} \mathrm{CP} / \mathrm{MAS}$ refocused INADEQUATE spectrum were recorded using proton $90^{\circ}$ pulse length of 5 us and a contact time of $2 \mathrm{~ms}$ and with a rotor synchronized delay of $1.9 \mathrm{~ms}$. The ${ }^{13} \mathrm{C}$ chemical shift was referred to adamantane.

4.5. Catalytic tests. The catalyst was pelletized, crushed and sieved into $0.2-0.4 \mathrm{~mm}$ particle size. $50 \mathrm{mg}$ of sample was mixed with $2 \mathrm{~g}$ quartz (Fluka) before being introduced into the fixed-bed reactor ( 7 $\mathrm{mm}$ diameter $) \mathrm{N}_{2}(30 \mathrm{~mL} / \mathrm{min})$ was bubbled in methanol held at $17^{\circ} \mathrm{C}$, giving a WHSV $=0.8 \mathrm{~h}^{-1}$. The catalyst was first activated with a nitrogen flow of $80 \mathrm{~mL} / \mathrm{min}$ for $1 \mathrm{~h}$ at $540^{\circ} \mathrm{C}$, and then the temperature was decreased to reaction conditions $\left(350\right.$ or $\left.400^{\circ} \mathrm{C}\right)$. Each experiment was analyzed every $5 \mathrm{~min}$ with an online gas chromatograph (Bruker 450GC, with PONA and $\mathrm{Al}_{2} \mathrm{O}_{3}-\mathrm{Plot}$ capillary columns, and two FID detectors). Conversion and selectivities were considered in carbon basis.

The MTO reaction using ${ }^{13} \mathrm{C}$-labelled methanol as substrate was conducted simulating the real reaction conditions. $150 \mathrm{mg}$ pelletized sample (0.2-0.4 mm) was mixed with $2 \mathrm{~g}$ quartz (0.6-0.8 $\mathrm{mm}$ Fluka) before being introduced into the fix-bed reactor $(7 \mathrm{~mm}$ diameter). $\mathrm{N}_{2}(90 \mathrm{~mL} / \mathrm{min})$ was bubbled in methanol held at $-17^{\circ} \mathrm{C}$, giving a WHSV $=0.8 \mathrm{~h}^{-1}$. The catalyst was first activated with a nitrogen flow of $80 \mathrm{~mL} / \mathrm{min}$ for $1 \mathrm{~h}$ at $540^{\circ} \mathrm{C}$, and then the temperature was decreased to reaction conditions $\left(350\right.$ or $\left.400^{\circ} \mathrm{C}\right)$. The feed was stopped at 2 or 20 min time on stream and the reactor 
was cooled down to quench the reaction. Catalyst was loaded in a glove box into the rotor of ${ }^{13} \mathrm{C}$-NMR spectra for measurement.

\section{AUTHOR INFORMATION}

\section{Corresponding Author}

Avelino Corma, acorma@itq.upv.es

Mercedes Boronat, boronat@itq.upv.es

\section{ORCID}

Pau Ferri: 0000-0001-8245-1662

Chengeng Li: 0000-0003-2004-5081

Cecilia Paris: 0000-0002-5673-8114

Alejandro Vidal-Moya: 0000-0002-8381-2383

Manuel Moliner: 0000-0002-5440-716X

Mercedes Boronat: 0000-0002-6211-5888

Avelino Corma: 0000-0002-2232-3527

Notes

The authors declare no competing financial interest.

\section{ASSOCIATED CONTENT}

\section{Supporting Information}

Experimental details on synthesis of OSDA and zeolites. DFT calculated Gibbs free energies and equilibrium constants. Physicochemical properties and characterization (XRD, TEM, ${ }^{27} \mathrm{Al}$ MAS NMR) of the catalyst samples used. Conversion and selectivity obtained at different $\mathrm{T}$ and using different catalyst samples. ${ }^{13} \mathrm{C}$ MAS NMR spectra and $2 \mathrm{D}{ }^{13} \mathrm{C} \quad \mathrm{CP} / \mathrm{MAS}$ refocused INADEQUATE of the retained organic species after reaction. Total energies and cartesian coordinates of all structures. This information is available free of charge on the ACS Publications website.

\section{ACKNOWLEDGMENT}

This work has been supported by the European Union through ERC-AdG-2014-671093 (SynCatMatch), Spanish Government through "Severo Ochoa" (SEV-2016-0683, MINECO), MAT2017-82288-C2-1-P (AEI/FEDER, UE) and RTI2018101033-B-I00 (MCIU/AEI/FEDER, UE), and by the Fundación Ramón Areces through a research contract (CIVP18A3908). The Electron Microscopy Service of the UPV is acknowledged for their help in sample characterization. Red Española de Supercomputación (RES) and Servei d'Informàtica de la Universitat de València are acknowledged for computational resources and technical support. C.L. acknowledges China Scholarship Council (CSC) for a Ph.D fellowship. P.F. thanks ITQ for a contract. The authors thank Prof. Fernando Rey and Dr. Joaquín Martínez for helpful discussions.

\section{REFERENCES}

(1) Stöcker, M. Methanol-to-hydrocarbons: catalytic materials and their behavior. Micropor. Mesopor. Mater. 1999, 29, 3-48.

(2) Tian, J. P.; Wei, Y.; Ye, M.; Liu, Z. Methanol to Olefins (MTO): From Fundamentals to Commercialization. ACS Catal. 2015, 5, 1922-1938.

(3) Olsbye, U.; Svelle, S.; Bjørgen, M.; Beato, P.; Janssens, T. V. W.; Joensen, F.; Bordiga, S.; Lillerud, K. P. Conversion of Methanol to Hydrocarbons: How Zeolite Cavity and Pore Size Controls Product Selectivity. Angew. Chem., Int. Ed. 2012, 51, 5810-5831.
(4) Haw, J. F.; Song, W.; Marcus, D. M.; Nicholas, J. B. The Mechanism of Methanol to Hydrocarbon Catalysis. Acc. Chem. Res. 2003, 36, 317-326

(5) Yarulina, I.; Chowdhury, A. D.; Meirer, F.; Weckhuysen, B. M.; Gascón, J. Recent trends and fundamental insights in the methanol-to-hydrocarbons process. Nature Catalysis 2018, 1, 398-411.

(6) Moliner, M.; Martínez, C.; Corma, A. Synthesis Strategies for Preparing Useful Small Pore Zeolites and Zeotypes for Gas Separations and Catalysis. Chem. Mater. 2014, 26, 246-258.

(7) Sun, Q.; Wang, N.; Bai, R.; Chen, G.; Shi, Z.; Zou, Y.; Yu, J. Mesoporogen-Free Synthesis of Hierarchical SAPO-34 with Low Template Consumption and Excellent Methanol-to-Olefin Conversion. ChemSusChem 2018, 11, 3812-382.

(8) Lesthaeghe, D.; De Sterck, B.; Van Speybroeck, V.; Marin, G. B.; Waroquier, M. Zeolite Shape-Selectivity in the gemMethylation of Aromatic Hydrocarbons. Angew. Chem. Int. Ed. 2007, 46, $1311-1314$

(9) McCann, D. M.; Lesthaeghe, D.; Kletnieks, P. W.; Guenther, D. R.; Hayman, M. J.; Van Speybroeck, V.; Waroquier, M.; Haw, J. F. A Complete Catalytic Cycle for Supramolecular Methanol-toOlefins Conversion by Linking Theory with Experiment, Angew. Chem. Int. Ed. 2008, 47, 5179-5182.

(10) Lesthaeghe, D.; Horré, A.; Waroquier, M.; Marin, G. B.; VanSpeybroeck, V. Theoretical Insights on Methylbenzene SideChain Growth in ZSM-5 Zeolites for Methanol-to-Olefin Conversion. Chem. Eur. J. 2009, 15, 10803-10808.

(11) Wang, C. M.; Wang,Y. D.; Xie, Z. K.; Liu, Z. P. Methanol to Olefin Conversion on HSAPO-34 Zeolite from Periodic Density Functional Theory Calculations: A Complete Cycle of Side Chain Hydrocarbon Pool Mechanism. J. Phys. Chem. C 2009, 113, 4584 4591 .

(12) De Wispelaere, K.; Hemelsoet, K.; Waroquier, M.; Van Speybroeck, V. Complete low-barrier side-chain route for olefin formation during methanol conversion in H-SAPO-34. J. Catal. 2013, 305, 76-80.

(13) Hemelsoet, K.; Van der Mynsbrugge, J.; De Wispelaere, K.; Waroquier, M.; Van Speybroeck, V. Unraveling the Reaction Mechanisms Governing Methanol-to-Olefins Catalysis by Theory and Experiment. ChemPhysChem 2013, 14, 1526-1545

(14) Ilias, S.; Bhan, A. Mechanism of the Catalytic Conversion of Methanol to Hydrocarbons. ACS Catal. 2012, 3, 18-31.

(15) Li, X.; Sun, Q.; Li, Y.; Wang, N.; Lu, J.; Yu, Y. Confinement Effect of Zeolite Cavities on Methanol-to-Olefin Conversion: A Density Functional Theory Study. J. Phys. Chem. C 2014, 118, 24935-24940.

(16) Wang, C. M.; Wang, Y. D.; Xie, Z. K. Verification of the Dual Cycle Mechanism for Methanol-to-Olefin Conversion in HSAPO34: a Methylbenzene-Based Cycle from DFT Calculations. Catal. Sci. Technol. 2014, 4, 2631-2638.

(17) Xu, S.; Zheng, A.; Wei, Y.; Chen, J.; Li, J.; Chu, Y.; Zhang, M.; Wang, Q.; Zhou, Y.; Wang, J.; Deng, F.; Liu, Z. Direct Observation of Cyclic Carbenium Ions and Their Role in the Catalytic Cycle of the Methanol-to-Olefin Reaction over Chabazite Zeolites. Angew. Chem., Int. Ed. 2013, 52, 11564-11568.

(18) Chen, J.; Li, J.; Yuan, C.; Xu, S.; Wei, Y.; Wang, Q.; Zhou, Y.; Wang, J.; Zhang, M.; He, Y.; Xu, S.; Liu, Z. Elucidating the olefin formation mechanism in the methanol to olefin reaction over AlPO-18 and SAPO-18. Catal. Sci. Technol., 2014, 4, 3268-3277. (19) Li, J.; Wei, Y.; Chen, J.; Xu, S.; Tian, P.; Yang, X.; Li, B.; Wang, J.; Liu, Z. Cavity Controls the Selectivity: Insights of Confinement Effects on MTO Reaction. ACS Catal. 2015, 5, 661665.

(20) Li, J.; Wei, Y.; Chen, J.; Tian, P.; Su, X.; Xu, S.; Qi, Y.; Wang, Q.; Zhou, Y.; He, Y.; Liu, Z. Observation of Heptamethylbenzenium Cation over SAPO-Type Molecular Sieve 
DNL-6 under Real MTO Conversion Conditions. J. Am. Chem. Soc. 2012, 134, 836-839.

(21) Zhang, W.; Chen, J.; Xu, S.; Chu, Y.; Wei, Y.; Zhi, Y.; Huang, J.; Zheng, A.; Wu, X.; Meng, X.; Xiao, F.; Deng, F.; Liu, Z. Methanol to Olefins Reaction over Cavity-type Zeolite: Cavity Controls the Critical Intermediates and Product Selectivity. ACS catal. 2018, 8, 10950-10963.

(22) Bhawe, Y.; Moliner-Marin, M.; Lunn, J. D.; Liu, Y.; Malek, A.; Davis, M. Effect of Cage Size on the Selective Conversion of Methanol to Light Olefins. ACS Catal. 2012, 2, 2490-2495.

(23) Kang, J. H.; Walter, R.; Xie, D.; Davis, T.; Chen, C. Y.; Davis, M. E.; Zones, S. I. Further Studies on How the Nature of Zeolite Cavities That Are Bounded by Small Pores Influences the Conversion of Methanol to Light Olefins. ChemPhysChem 2018, $19,412-419$.

(24) Kang, J. H.; Alshafei, F. H.; Zones, S. I.; Davis, M. E. CageDefining Ring: A Molecular Sieve Structural Indicator for Light Olefin Product Distribution from the Methanol-to-Olefins Reaction. ACS Catal. 2019, 9, 6012-6019.

(25) Hereijgers, B. P. C.; Bleken, F.; Nilsen, M. H.; Svelle, S.; Lillerud, K. P.; Bjørgen M.; Weckhuysen, B. M.; Olsbye, U. Product shape selectivity dominates the Methanol-to-Olefins (MTO) reaction over H-SAPO-34 catalysts. J. Catal. 2009, 264, 77-87.

(26) Wang, C. M.; Wang, Y. D.; Du, Y. J.; Yang, G.; Xie, Z. K. Similarities and differences between aromatic-based and olefinbased cycles in H-SAPO-34 and H-SSZ-13 for methanol-to-olefins conversion: insights from energetic span model. Catal. Sci. Technol. 2015, 5, 4354-4364.

(27) Wang, C. M.; Wana, Y. D.; Liu, H. X.; Xie, Z. K.; Liu, Z. P. Theoretical Insight into the Minor Role of Paring Mechanism in the Methanol-to-Olefin Conversion within H-SAPO-34 Catalyst. Micropor. Mesopor. Mater. 2012, 158, 264-271.

(28) Gallego, E. M.; Portilla, M. T.; Paris, C.; León-Escamilla, A.; Boronat, M.; Moliner, M.; Corma, A. "Ab initio" synthesis of zeolites for preestablished catalytic reactions. Science 2017, 355, 1051-1054

(29) Li, C.; Paris, C.; Martinez-Triguero, J.; Boronat, M.; Moliner, M.; Corma, A. Synthesis of reaction-adapted zeolites as methanolto-olefins catalysts with mimics of reaction intermediates as organic structure-directing agents. Nature Catalysis 2018, 1, 547554.

(30) Song, W.; Fu, H.; Haw, J. F. Supramolecular Origins of Product Selectivity for Methanol-to-Olefin Catalysis on HSAPO34. J. Am. Chem. Soc. 2001, 123, 4749-4754.

(31) Hwang, A.; Johnson, B. A.; Bhan, A. Mechanistic study of methylbenzene dealkylation in methanol-to-olefins catalysis on HSAPO-34. J. Catal. 2019, 369, 86-94.

(32) Arstad, B.; Nicholas, J. B.; Haw, J. F. Theoretical Study of the Methylbenzene Side-Chain Hydrocarbon Pool Mechanism in
Methanol to Olefin Catalysis. J. Am. Chem. Soc. 2004, 126, 29913001 .

(33) Martin, N.; Li, Z.; Matrinez-Triguero, J.; Yu, J.; Moliner, M.; Corma, A.; Nanocrystalline SSZ-39 zeolite as an efficient catalyst for the methanol-to-olefin (MTO) process. Chem. Commun. 2016, $52,672-675$.

(34) Gallego, E. M.; Li, C.; Paris, C.; Martín, N.; Li, Z.; MartínezTriguero, Boronat, M.; Moliner, M.; Corma, A. Nanocrystalline SSZ-39 zeolite as an efficient catalyst for the methanol-to-olefin (MTO) process. Chem. Eur. J. 2018, 24, 14631-14635.

(35) Wang, C.; Li, B.; Wang, Y.; Xie, Z. Insight into the Topology Effect on the Diffusion of Ethene and Propene in Zeolites: A Molecular Dynamics Simulation Study. J. Energy Chem. 2013, 22, 914-918.

(36) Ghysels, A.; Moors, S. L. C.; Hemelsoet, K.; De Wispelaere, K.; Waroquier, M.; Sastre, G.; Van Speybroeck, V. ShapeSelective Diffusion of Olefins in 8-Ring Solid Acid Microporous Zeolites. J. Phys. Chem. C 2015, 119, 23721-23734

(37) Zhao, Y.; Truhlar, D. G. The M06 suite of density functionals for main group thermochemistry, thermochemical kinetics, noncovalent interactions, excited states, and transition elements: two new functionals and systematic testing of four M06-class functionals and 12 other functionals. Theor. Chem. Acc. 2008, 120, 215-241.

(38) a) Ditchfield, R.; Hehre, W. J.; Pople. Self-Consistent Molecular-Orbital Methods. IX. An Extended Gaussian-Type Basis for Molecular-Orbital Studies of Organic Molecules. J. A. J. Chem. Phys. 1971, 54, 724-728. b) Hehre, W. J.; Ditchfield, R.; Pople. Self - Consistent Molecular Orbital Methods. XII. Further Extensions of Gaussian-Type Basis Sets for Use in Molecular Orbital Studies of Organic Molecules, J. A. J. Chem. Phys. 1972 $56,2257-2261$.

(39) Gaussian 09, M. J. Frisch, G. W. Trucks, H. B. Schlegel, G. E. Scuseria, M. A. Robb, J. R. Cheeseman, G. Scalmani, V. Barone, G. A. Petersson, H. Nakatsuji, X. Li, M. Caricato, A. Marenich, J. Bloino, B. G. Janesko, R. Gomperts, B. Mennucci, H. P. Hratchian, J. V. Ortiz, A. F. Izmaylov, J. L. Sonnenberg, D. Williams-Young, F. Ding, F. Lipparini, F. Egidi, J. Goings, B. Peng, A. Petrone, T. Henderson, D. Ranasinghe, V. G. Zakrzewski, J. Gao, N. Rega, G. Zheng, W. Liang, M. Hada, M. Ehara, K. Toyota, R. Fukuda, J. Hasegawa, M. Ishida, T. Nakajima, Y. Honda, O. Kitao, H. Nakai, T. Vreven, K. Throssell, J. A. Montgomery, Jr., J. E. Peralta, F. Ogliaro, M. Bearpark, J. J. Heyd, E. Brothers, K. N. Kudin, V. N. Staroverov, T. Keith, R. Kobayashi, J. Normand, K. Raghavachari, A. Rendell, J. C. Burant, S. S. Iyengar, J. Tomasi, M. Cossi, J. M. Millam, M. Klene, C. Adamo, R. Cammi, J. W. Ochterski, R. L. Martin, K. Morokuma, O. Farkas, J. B. Foresman, and D. J. Fox, Gaussian, Inc., Wallingford CT, 2016.

(40) Reed, A. E.; Weinstock, R. B.; Weinhold, F. Natural Population Analysis. J. Chem. Phys. 1985, 83, 735-747. 


\section{A Chemical and Structural Parameter Connecting Cavity Architecture, Confined Hydrocarbon Pool Species and MTO Product Selectivity in Small-Pore Cage-Based Zeolites}

Pau Ferri, ${ }^{\dagger}$ Chengeng Li,${ }^{\dagger}$ Cecilia Paris, Alejandro Vidal-Moya, Manuel Moliner, Mercedes Boronat ${ }^{*}$ and Avelino Corma*

Instituto de Tecnología Química, Universitat Politècnica de València - Consejo Superior de Investigaciones Cientificas, Av. de los Naranjos, s/n, 46022 Valencia, Spain

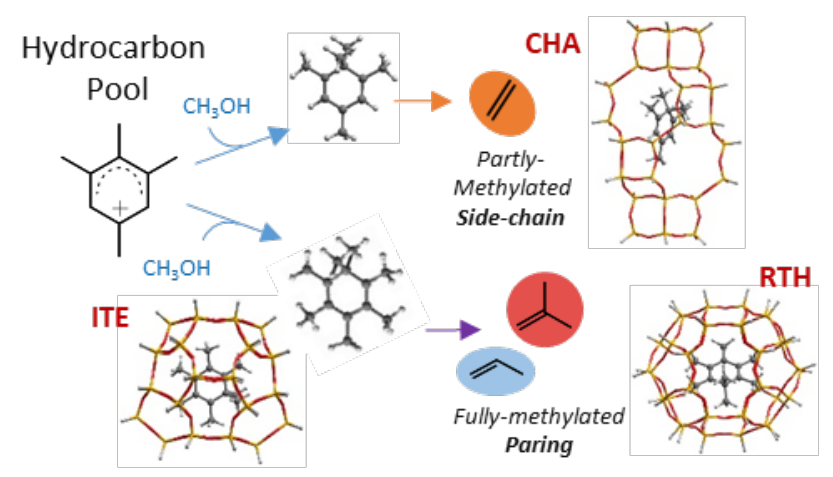

